\title{
O envelhecimento na atualidade: aspectos cronológicos, biológicos, psicológicos e sociais
}

\author{
The process of aging in today's world: chronological, \\ biological, psychological and social aspects
}

\author{
Rodolfo Herberto SCHNEIDER' \\ Tatiana Quarti IRIGARAY
}

\begin{abstract}
Resumo
O objetivo deste artigo é indicar aspectos que configuram o processo de envelhecimento na sociedade atual, especificamente as diferentes conceituações utilizadas para definir este processo em relação aos aspectos cronológicos, biológicos, psicológicos e sociais envolvidos. A partir desta revisão da literatura, conclui-se que a idade cronológica não é a única forma de mensurar o processo de envelhecimento, sendo este uma interação de fatores complexos que apresentam uma influência variável sobre o indivíduo e que podem contribuir para a variação das intempéries da passagem do tempo. Biologicamente, os eventos ocorrem ao longo de certo período, mas não necessariamente o tempo é a causa destes eventos.
\end{abstract}

Unitermos: Crenças em relação à velhice. Fases de ciclo da vida. Idoso.

\begin{abstract}
The aim of this study is to indicate aspects that characterize the aging process in today's society, specifically the different conceptualizations used to define this process with regard to the chronological, biological, psychological and social aspects involved. Through this review of the literature, it may be concluded that chronological age is not the only way of measuring the aging process, this being an interaction of complex factors which have a variable influence on the individual and which may contribute to the inconstant inclemency of the passage of time. Thus, biologically, events occur over a certain period of time, but time is not necessarily the cause of these events.
\end{abstract}

Uniterms: Beliefs toward aging. Life cycle stages. Aged.

A etapa da vida caracterizada como velhice, com suas peculiaridades, só pode ser compreendida a partir da relação que se estabelece entre os diferentes aspectos cronológicos, biológicos, psicológicos e sociais. Essa interação institui-se de acordo com as condições da cultura na qual o indivíduo está inserido. Condições históricas, políticas, econômicas, geográficas e culturais produzem diferentes representações sociais da velhice e também do idoso. Há uma correspondência entre a concepção de velhice presente em uma sociedade e as atitudes frente às pessoas que estão envelhecendo.

O pressuposto deste estudo é analisar os aspectos envolvidos no processo de envelhecimento, enfocando a importância do contexto social na

1 Pontifícia Universidade Católica do Rio Grande do Sul, Instituto de Geriatria e Gerontologia. Av. Ipiranga, 6690, 30 andar, Jardim Botânico, 90610-000, Porto Alegre, RS, Brasil. Correspondência para/Correspondence to: T.Q. IRIGARAY. E-mail: <tati.irigaray@ig.com.br>. 
determinação da idade da velhice, pois indivíduo e sociedade estão relacionados diretamente. A relação entre os aspectos cronológicos, biológicos, psicológicos e culturais é fundamental na categorização de um indivíduo como velho ou não. A pessoa mais velha, na maioria das vezes, é definida como idosa quando chega aos 60 anos, independentemente de seu estado biológico, psicológico e social. Entretanto, o conceito de idade é multidimensional e não é uma boa medida do desenvolvimento humano. A idade e o processo de envelhecimento possuem outras dimensões e significados que extrapolam as dimensões da idade cronológica.

Em todo o mundo, o número de pessoas com 60 anos ou mais está crescendo mais rapidamente do que o de qualquer outra faixa etária em todo o mundo. A população de idosos, pessoas com 60 anos ou mais, cresceu 7,3 milhões entre 1980 e 2000, totalizando mais de 14,5 milhões em 2000. O Brasil, até 2025, será o sexto país em número de idosos (World Health Organization - WHO, 2005).

O aumento do número de anos é decorrente da redução nas taxas de fertilidade e do acréscimo da longevidade nas últimas décadas. Em todo o mundo, observam-se quedas abruptas nas taxas de fertilidade. Além disso, estima-se que, até 2025, 120 países terão alcançado taxas de fertilidade total abaixo do nível de reposição (média de fertilidade de 2,1 crianças por mulher). Atualmente, 70 países já possuem taxa de fertilidade menor que o nível de reposição, sendo que em 1975 apenas 22 países possuíam esse índice (WHO, 2005).

Atualmente, os especialistas no estudo do enveIhecimento referem-se a três grupos de pessoas mais velhas: os idosos jovens, os idosos velhos e os idosos mais velhos. O termo idosos jovens geralmente se refere a T. I. pessoas de 65 a 74 anos, que costumam estar ativas, 乞 cheias de vida e vigorosas. Os idosos velhos, de 75 a 84 anos, e os idosos mais velhos, de 85 anos ou mais, são aqueles que têm maior tendência para a fraqueza e para a enfermidade, e podem ter dificuldade para desempenhar algumas atividades da vida diária (Papalia, Olds \& Feldman, 2006). Embora esta categorização seja bastante usual, cada vez mais as pesquisas revelam que o processo de envelhecimento é uma experiência heterogênea, vivida como uma experiência individual. Algumas pessoas, aos 60 anos, já apresentam alguma incapacidade; outras estão cheias de vida e energia aos 85 anos (Bee, 1997).

Outra classificação muito usada é por idade funcional, isto é, o quão bem uma pessoa funciona em um ambiente físico e social em comparação a outras de mesma idade cronológica. Por exemplo, uma pessoa de 90 anos com boa saúde física pode ser funcionalmente mais jovem do que uma de 65 anos que não está (Papalia et al., 2006). A distinção entre idosos jovens, idosos velhos e idosos mais velhos pode auxiliar no entendimento de que o envelhecimento não é algo determinado pela idade cronológica, mas é conseqüência das experiências passadas, da forma como se vive e se administra a própria vida no presente e de expectativas futuras; é, portanto, uma integração entre as vivências pessoais e o contexto social e cultural em determinada época, e nele estão envolvidos diferentes aspectos: biológico, cronológico, psicológico e social.

\section{Imagens da velhice}

Mesmo nos dias atuais, o envelhecimento aparece associado a doenças e perdas, e é na maioria das vezes entendido como apenas um problema médico. Para Neri e Freire (2000), o envelhecimento ainda está ligado à deterioração do corpo, ao declínio e à incapacidade. "Na base da rejeição ou da exaltação acrítica da velhice, existe uma forte associação entre esse evento do ciclo vital com a morte, a doença, o afastamento e a dependência" (Neri \& Freire, 2000, p. 8). A velhice começou a ser tratada como uma etapa da vida caracterizada pela decadência física e ausência de papéis sociais a partir da segunda metade do século XIX. O avançO da idade dar-se-ia como um processo contínuo de perdas e de dependência, que daria uma identidade de falta de condições aos idosos e seria responsável por um conjunto de imagens negativas associadas à velhice (Debert, 1999).

As associações negativas relacionadas à velhice atravessaram os séculos e, ainda hoje, mesmo com tantos recursos para prevenir doenças e retardá-la, é temida por muitas pessoas e vista como uma etapa detestável. A célebre frase de uma artista brasileira idosa famosa,"o envelhecimento é a prova de que o inferno existe" (grifo nosso), demonstra o quanto a velhice é uma 
experiência individual que pode ser vivenciada de forma positiva ou negativa, em consonância com a história de vida da pessoa e da representação de velhice que está enraizada na sociedade em que vive. Assim, pode-se inferir que não importa a quantidade de anos que o indivíduo tem, mas sim, o que ele fez com os anos vividos, e como a sociedade trata alguém com aquela idade.

Estudos realizados em sociedades não ocidentais apresentam imagens positivas da velhice e do envelhecimento, ensinando que a representação de velhice enraizada nas idéias de deterioração e perda não é universal. À medida que o envelhecimento é documentado em outros povos, constata-se que ele é um fenômeno profundamente influenciado pela cultura (Uchôa, 2003).

As concepções de velhice nada mais são do que resultado de uma construção social e temporal feita no seio de uma sociedade com valores e princípios próprios, que são atravessados por questões multifacetadas, multidirecionadas e contraditórias. Na época contemporânea, florescer do século XXI, ao mesmo tempo em que a sociedade potencializa a longevidade, ela nega aos velhos o seu valor e sua importância social. Vive-se em uma sociedade de consumo na qual apenas o novo pode ser valorizado, caso contrário, não existe produção e acumulação de capital. Nesta dura realidade, o velho passa a ser ultrapassado, descartado, ou já está fora de moda. Pode-se entender um pouco mais a dinâmica da sociedade atual nas palavras de Pacheco (2005), que toma como exemplo o fenômeno dos aparelhos celulares:

Em poucos anos, eles se modificaram centenas de vezes. Desenhos modernos, bonitos e funcionais são criados para que as pessoas pareçam antenadas, jovens e bem-sucedidas. O medo da transformação que surge com a velhice assemelha-se um pouco ao fenômeno dos celulares. Tem-se medo de envelhecer como se tem receio de ser ridicularizado ao usar o aparelho antigo de dez anos, como os tijolões dos 'tiozinhos'. O ser humano envelhecido é-nos apresentado, pela ideologia dominante, como o aparelho ultrapassado. Fala, mas ninguém quer! (p. 65).

O status reduzido das pessoas idosas é também devido à ênfase contemporânea na juventude, beleza, autonomia, independência e na habilidade de ser produtivo ou reprodutivo. Assim, "ser velho" assume uma conotação negativa, remetendo à perda de atributos tão valorizados pelo meio social e, simultaneamente, pelo próprio idoso. Para Jones (2006), o significado social relacionado às pessoas mais velhas é amplamente negativo, embora não seja exclusivamente assim. Os estereótipos negativos são atribuídos principalmente pelos próprios idosos, que não se reconhecem como tal e falam da categoria "velho" como se não fizessem parte da mesma. Tal atitude seria uma falsa consciência ou uma atitude preconceituosa?

Por que a percepção da maioria das pessoas sobre os idosos é pior do que a realidade? Por que muitos têm preconceito contra os idosos e a velhice? Uma das razões, segundo Berger (1994), é que a cultura nos Estados Unidos enfatiza o crescimento, a força e o progresso, com uma exagerada veneração aos jovens. Outra explicação dada por ele é que, para muitas pessoas, interagir com velhos é lembrar-se da proximidade com a morte. Assim, o preconceito serviria como fator protetor porque manteria afastadas as idéias de declínio e de morte. De acordo com Papalia et al. (2006), o envelhecimento é visto em diversas culturas como indesejável. Os estereótipos refletem idéias errôneas comuns, como: as pessoas idosas são doentes, são rabugentas e excêntricas. Esses estereótipos são prejudiciais e geram uma imagem distorcida da velhice, pois se sabe que a maioria dos idosos não é doente, além de apresentarem dimensões de personalidade que teceram ao longo de toda a vida.

Para Helman (2005), na sociedade moderna as pessoas idosas tendem a ter um status muito mais baixo, pois, atualmente, é o jovem que freqüentemente tem maiores habilidades e um conhecimento mais amplo em determinadas áreas da vida. Os jovens são mais hábeis para absorver e compreender as últimas inovações tecnológicas, e em uma velocidade muito mais rápida. Eles têm acesso a muito mais fontes exteriores de conhecimento do que tiveram seus pais e avós pelos meios de comunicação, livros e internet.

Embora a velhice seja nada além do que um construto social, o preconceito continua florescendo. A idade é uma categoria embutida dentro dela mesma, é discutível e obsoleta. Enquanto todos os outros estágios da vida são planejados e construídos social e culturalmente e não existem conflitos para eliminar a infância, a adolescência e a idade adulta do panorama do 
desenvolvimento humano, a velhice é colocada à margem (Andrews, 1999), pois ao mesmo tempo em que as pessoas querem viver muito, não querem ficar velhas nem se parecer com velhos.

\section{Qual o nome da velhice?}

Atualmente, percebe-se uma proliferação dos termos utilizados para se referir às pessoas que já viveram mais tempo ou à fase da vida anteriormente chamada apenas de velhice. Entre os termos mais comuns estão: terceira idade, melhor idade, adulto maduro, idoso, velho, meia-idade, maturidade, idade maior e idade madura (Neri \& Freire, 2000).

Ainda é comum que a maioria das pessoas mais velhas resista a ser chamada de velha. Segundo Ferreira (2000), a palavra "velho" significa muito idoso, antigo, gasto pelo tempo, experimentado, veterano, que há muito tempo exerce uma profissão ou tem certa qualidade, desusado, obsoleto. Nesta breve definição, percebem-se os vários sentidos negativos da palavra velho como algo já ultrapassado, descartado e fora de moda. De acordo com Gibson (2000), atitudes preconceituosas e estereótipos sociais estão também incorporados na linguagem e, provavelmente, levarão muitos anos para ocorrerem mudanças nesse sentido. Para ele, a palavra velho não significa decrepitude, desgaste, fora de moda, mas simplesmente se refere ao número de anos que a pessoa viveu.

A palavra terceira idade, atualmente tão usada, teve sua origem na França, na década de 1960, e era utilizada para descrever a idade em que a pessoa se aposentava. A primeira idade seria a infância, que traduziria uma idéia de improdutividade, mas com possibilidade de crescimento. Já a segunda idade seria a vida adulta, etapa produtiva. Na época em que a expressão terceira idade foi criada, procurou-se garantir a atividade das pessoas depois da aposentadoria, que ocorria na França por volta dos 45 anos. Com o avanço contínuo da esperança de vida, a expressão "terceira idade" passou a designar a faixa etária intermediária, entre a vida adulta e a velhice (Neri \& Freire, 2000). Desta forma, o uso do termo terceira idade torna-se inadequado para descrever o grupo de indivíduos com 60 anos ou mais, e traz ainda uma conotação negativa ao termo velhice, porque se compreende que quem está na terceira idade ainda não é velho (Araújo \& Carvalho, 2005). Para Prado (2002), terceira idade é uma criação recente no mundo ocidental. "O fenômeno do envelhecimento populacional, marcante no século XX, empurrou a velhice para idades mais avançadas" (p. 12).

Os termos "amadurecer" e "idade madura" também são muito utilizados e significam a sucessão de mudanças ocorridas no organismo e a conquista de papéis sociais e de comportamentos considerados próprios ao adulto mais velho (Neri \& Freire, 2000). "A preferência por termos como terceira idade ou idade madura pode parecer um eufemismo, palavra de origem grega que significa soar bem" (p.14). O uso de tantos termos e expressões tem por objetivo "soar bem, mascarando o preconceito e negando a realidade. Se não houvesse preconceito, não seria necessário disfarçar nada por meio de palavras" (p.18). Segundo as mesmas autoras, as pessoas que viveram mais tempo devem ser chamadas simplesmente de velhas ou idosas.

As palavras, na maioria das vezes, trazem consigo uma forte associação. O termo pensionista, no Reino Unido, é muitas vezes usado como sinônimo de pessoa velha. Lá, é esperado que as avós sejam, por excelência, pessoas velhas. Assim, há uma estreita relação entre ser pensionista, ser avó e ser uma pessoa velha (Bytheway, 1995).

Palavras como old, older, elderly e referências de idade cronológica podem posicionar alguém como velho, mas cada caso precisa ser visto individualmente dentro de realidades próprias (Bytheway, 2000). Posicionar alguém como velho requer atenção a cada detalhe. O posicionamento de alguém como idoso não pode ser simplesmente respondido pela ocorrência de palavras como "avó" ou referência de idade cronológica. Muitas frases que deveriam ser esperadas para posicionar alguém como velho não fazem sentido dentro de todas as circunstâncias. Por exemplo, em algumas situações particulares, tais como um encontro de centenários, ser descrito com 90 anos posiciona alguém como relativamente jovem. As palavras "avó", "aposentado" e "pensionista" suscitam controvérsias na realidade brasileira porque elas não são sinônimas de "ser velho". Avô pode ser alguém aos 30 anos ou até um milionário que pode ter se aposentado aos 35 anos (Jones, 2006).

A existência de múltiplas palavras para nomear a velhice revela o quanto o processo de envelhecimento 
é complexo, negado, evitado ou mesmo temido. Evidencia claramente a existência de preconceitos, tanto por parte da pessoa idosa quanto da sociedade. As pessoas idosas e a sociedade em geral precisam se reeducar quanto à superação de idéias preconceituosas, pois se tornar velho é aceitar a velhice e ser orgulhoso dos muitos anos que conferem experiência, sabedoria e liberdade.

\section{As idades da velhice}

Determinar o início da velhice é uma tarefa complexa porque é difícil a generalização em relação à velhice, e há distinções significativas entre diferentes tipos de idosos e velhices. A idade é um fato prédeterminado, mas o tratamento dado aos anos depende das características da pessoa. Assim, torna-se difícil saber que critérios utilizar para se definir o início da velhice, pois os aspectos que caracterizam este período são questões ainda controversas que provocam inúmeras discussões entre os profissionais, atraindo a atenção de estudiosos.

Na realidade, existem diferentes formas de se definir e conceituar a velhice. Uma delas é a definição preconizada pela Organização Mundial da Saúde, que é baseada na idade cronológica, na qual a definição de idoso inicia aos 65 anos nos países desenvolvidos e aos 60 anos nos países em desenvolvimento. No Brasil, de acordo com o Estatuto do Idoso (2003), as pessoas com idade igual ou superior a 60 anos são reconhecidas como idosas. Entretanto, alguns direitos como a gratuidade no transporte coletivo público urbano e semi-urbano só é concedida aos maiores de 65 anos.

O envelhecimento humano, cada vez mais, é entendido como um processo influenciado por diversos fatores, como gênero, classe social, cultura, padrões de saúde individuais e coletivos da sociedade, entre outros.

Para San Martín e Pastor (1996), não existe um consenso sobre o que se nomeia velhice porque as divisões cronológicas da vida do ser humano não são absolutas e não correspondem sempre às etapas do processo de envelhecimento natural. A velhice não é definida por simples cronologia, mas pelas condições físicas, funcionais, mentais e de saúde das pessoas, o que equivale a afirmar que podem ser observadas dife- rentes idades biológicas e subjetivas em indivíduos com a mesma idade cronológica.

Assim, a idade cronológica deixa de ser um marcador preciso para as mudanças que acompanham o envelhecimento, passando a ser apenas uma forma padronizada de contagem dos anos vividos, uma vez que existem variações de diferentes intensidades relacionadas ao estado de saúde, participação e níveis de independência entre pessoas mais velhas que possuem a mesma idade. Segundo alguns estudos, outros eventos, relacionados à vida pessoal, familiar e profissional servem de pontos de referência para mudanças. Desta forma, o envelhecimento humano pode ser compreendido como um processo complexo e composto pelas diferentes idades: cronológica, biológica, psicológica e social.

\section{Idade cronológica}

A idade cronológica, que mensura a passagem do tempo decorrido em dias, meses e anos desde o nascimento, é um dos meios mais usuais e simples de se obter informações sobre uma pessoa. Porém, o conceito de idade é multidimensional e, por isso, a idade cronológica não se torna uma boa medida da função desenvolvimental (Hoyer \& Roodin, 2003).

Para Schroots e Birren (1990), a idade cronológica pode ser entendida como algo absoluto e nela são fixadas propriedades que podem ser medidas. Ela é medida pelo tempo, empregando-se um padrão absoluto ou escalas de medida. Dada a comparação do tempo com medida, esta definição tende a obscurecer o fato de que o tempo não é fundamentalmente absoluto ou objetivo, mas relativo e subjetivo. Diferentes variáveis de tempo, como tempo histórico, idade (nascimento), coorte podem reduzir o mesmo conceito de tempo físico clássico. Entretanto, este modelo não apresenta necessariamente concomitância com a idade biológica no processo de envelhecimento. Andrews (2000) afirma que é absurdo insistir que a idade cronológica deve fazer parte da identidade. Ela, assim como outros aspectos de identidade, compreende dimensões objetivas e subjetivas.

A idade cronológica refere-se somente ao número de anos que tem decorrido desde o nascimento 
da pessoa, portanto não é um índice de desenvolvimento biológico, psicológico e social, pois ela por si só não causa o desenvolvimento. Segundo Hoyer e Roodin (2003), a idade é meramente um marcador aproximado do processo que influencia o comportamento ao longo do tempo.

\section{Idade biológica}

A idade biológica é definida pelas modificações corporais e mentais que ocorrem ao longo do processo de desenvolvimento e caracterizam o processo de envelhecimento humano, que pode ser compreendido como um processo que se inicia antes do nascimento do indivíduo e se estende por toda a existência humana.

As mudanças e as perdas fazem parte do enveIhecimento. A partir dos 40 anos, a estatura do indivíduo diminui cerca de um centímetro por década, principalmente devido à diminuição da altura vertebral ocasionada pela redução da massa óssea e outras alterações degenerativas da coluna vertebral. A pele fica mais fina e friável, menos elástica e com menos oleosidade. A visão também declina, principalmente para objetos próximos. A audição diminui ao longo dos anos, porém normalmente não interfere no dia-a-dia. Com o envelhecimento, o peso e o volume do encéfalo diminuem por perda de neurônios, mas, apesar desta redução, as funções mentais permanecem preservadas até o final da vida (Costa \& Pereira, 2005).

\section{Idade social}

A idade social é definida pela obtenção de hábitos e status social pelo indivíduo para o preenchimento de muitos papéis sociais ou expectativas em relação às pessoas de sua idade, em sua cultura e em seu grupo social. Um indivíduo pode ser mais velho ou mais jovem dependendo de como ele se comporta dentro de uma classificação esperada para sua idade em uma sociedade ou cultura particular. A medida da idade social é composta por performances individuais de papéis sociais e envolve características como tipo de vestimenta, hábitos e linguagem, bem como respeito social por parte de outras pessoas em posição de liderança. Ela também se relaciona com as idades cronológica e psicológica (Schroots \& Birren, 1990). Para
Neri (2005), "a idade social diz respeito à avaliação do grau de adequação de um indivíduo ao desempenho dos papéis e dos comportamentos esperados para as pessoas de sua idade, num dado momento da história de cada sociedade".

Por outro lado, o envelhecimento social deve ser entendido como um processo de mudanças de papéis sociais, no qual são esperados dos idosos comportamentos que correspondam aos papéis determinados para eles. Há papéis que são graduados por idade e que são típicos desta parte da vida. Diferentes padrões de vestir e falar são esperados de pessoas em diferentes idades, e o status social varia de acordo com as diferenças e de acordo com a idade (Schroots \& Birren, 1990).

A experiência de envelhecimento e velhice pode variar no tempo histórico de uma sociedade, pois o início dela é demarcado em cada época por critérios estabelecidos para agrupar categorias etárias (Neri \& Freire, 2000)."A sociedade não o faz com base em pura invenção, mas como resposta a mudanças evolutivas compartilhadas pela maioria das pessoas dos vários grupos etários, seja em virtude de determinação biológica, seja em virtude de determinação histórica e social" (p.14). A idade social corresponde, assim, aos comportamentos atribuídos aos papéis etários que a sociedade determina para os seus membros. Ela é composta por atributos que caracterizam as pessoas e que variam de acordo com a cultura, o gênero, a classe social, o transcorrer das gerações e das condições de vida e de trabalho, sendo que as desigualdades destas condições levam a desigualdades no processo de envelhecer. A cultura tem um importante papel nesse aspecto, pois define como uma sociedade vê os idosos e o processo de envelhecimento. Neri (2001a) afirma que a idade social diz respeito à avaliação do grau de adequação de um indivíduo ao desempenho dos papéis sociais e dos comportamentos esperados para as pessoas da sua idade em um dado momento da história de cada sociedade.

Socialmente, pode-se inferir que a pessoa é definida como idosa a partir do momento em que deixa o mercado de trabalho, isto é, quando se aposenta e deixa de ser economicamente ativa. A sociedade atribui aos aposentados o rótulo de improdutivos e inativos. Com a aposentadoria, muitas vezes se percebe um 
rompimento abrupto das relações sociais com outras pessoas com as quais o indivíduo conviveu durante muitos anos. Ocorre, ainda, uma redução salarial considerável e a falta de atividades alternativas fora do ambiente de trabalho.

Pacheco (2005) considera a aposentadoria "um rito de passagem para a velhice, ela acentua sua vinculação à terceira idade, numa sociedade de consumo na qual apenas o novo é cultuado como fonte da renovação, do desejo, da posse" (p. 65). Debert (1999) possui outro entendimento à medida que não considera a aposentadoria uma passagem para a velhice. Para essa autora, a aposentadoria deixou de ser um momento de descanso e recolhimento e tornou-se um período de atividade e lazer. Mais uma vez, percebe-se o quanto a velhice é uma experiência heterogênea e complexa, pois para alguns a aposentadoria pode significar o desengajamento da vida social e, para outros, o início de uma vida social prazerosa, composta por atividades e lazer.

\section{Idade psicológica}

O conceito de idade psicológica pode ser usado em dois sentidos. Um se refere à relação que existe entre a idade cronológica e às capacidades psicológicas, tais como percepção, aprendizagem e memória, as quais prenunciam o potencial de funcionamento futuro do indivíduo (Neri, 2005).

Hoyer e Roodin (2003) definem a idade psicológica como as habilidades adaptativas dos indivíduos para se adequarem às exigências do meio. As pessoas se adaptam ao meio pelo uso de várias características psicológicas, como aprendizagem, memória, inteligência, controle emocional, estratégias de coping etc. Há adultos que possuem tais características psicológicas com graus maiores que outros e, por isso, são considerados "jovens psicologicamente", e outros que possuem tais traços em graus menores e são considerados "velhos psicologicamente".

Em parte, a caracterização do indivíduo como velho é dada quando ele começa a ter lapsos de memória, dificuldade de aprendizado e falhas de atenção, orientação e concentração, comparativamente com suas capacidades cognitivas anteriores. Sabe-se que mesmo durante o processo de envelhecimento normal, algumas capacidades cognitivas como a rapidez de aprendizagem e a memória diminuem naturalmente com a idade. No entanto, essas perdas podem ser compensadas por ganhos em sabedoria, conhecimento e experiência. Felizmente, na maioria das vezes, o declínio no funcionamento cognitivo é provocado pelo desuso (falta de prática), doenças (como depressão), fatores comportamentais (como consumo de álcool e medicamentos), fatores psicológicos (por exemplo, falta de motivação, de confiança e baixas expectativas) e fatores sociais (como a solidão e o isolamento), mais do que o envelhecimento em si (WHO, 2005).

Estudo realizado por Argimon e Stein (2005) revela que o envelhecimento em si não ocasiona mudanças significativas nas habilidades cognitivas: "os idosos, apesar da idade avançada, apresentaram um desenvolvimento de habilidades cognitivas cujo declínio é de intensidade leve, não sendo suficiente para acarretar mudanças significativas no seu padrão cognitivo" (p. 71). Para essas autoras, um dos aspectos que poderia atuar como fator de proteção do declínio cognitivo é a escolaridade, já que "os idosos que tinham mais escolaridade conservaram um melhor resultado no período de três anos em muitas funções cognitivas examinadas" (p.70). Vê-se, também, que a senilidade não é um componente normal do envelhecimento. Desta forma, o idoso não perde a capacidade de raciocínio e a idade não leva ao declínio das funções intelectuais, uma vez que a presença de patologias, e não a idade em si, está envolvida na maior parte dos problemas que interferem nas habilidades cognitivas dos idosos.

Outro conceito de idade psicológica tem relação com o senso subjetivo de idade. Este conceito depende de como cada pessoa avalia a presença ou a ausência de marcadores biológicos, sociais e psicológicos do envelhecimento com outras pessoas de sua idade (Neri, 2005). O julgamento subjetivo, a estimação da duração de eventos ou a quantia de tempo decorrida compõem este conceito de idade psicológica, que se correlaciona diretamente com a idade cronológica e o meio.

A idade psicológica pode também ser definida pelos padrões de comportamento adquiridos e mantidos ao longo da vida e tem uma influência direta na forma como as pessoas envelhecem. O envelhecimento é resultado de uma construção que o indivíduo fez durante toda a vida. A auto-eficácia, que é a crença do 
indivíduo na capacidade de exercer controle sobre a própria vida, está relacionada às escolhas pessoais de comportamento durante o processo de envelhecimento e à preparação para a aposentadoria. Saber superar as adversidades determina o nível de adaptação a mudanças e a crises próprias do processo de envelhecimento (WHO, 2005)."Homens e mulheres que se preparam para a velhice e se adaptam a mudanças fazem um melhor ajuste em sua vida depois dos 60 anos" (p.27).

Estudos atuais sugerem que os idosos podem apresentar uma imensa capacidade de se adaptar a novas situações e de pensar estratégias que sirvam como fatores protetores. O conceito de resiliência, que pode ser definido como a capacidade de recuperação e manutenção do comportamento adaptativo mesmo quando ameaçado por um evento estressante, e o de plasticidade, caracterizado como o potencial para mudança, são vividos pelos idosos e constituem fatores indispensáveis para um envelhecimento bem-sucedido.

Neri (2001a) define a idade psicológica como "a maneira como cada indivíduo avalia em si mesmo a presença ou a ausência de marcadores biológicos, sociais e psicológicos da idade, com base em mecanismos de comparação social mediados por normas etárias" (p.43).

\section{Considerações Finais}

Dadas as diferentes dimensões de idade que compõem o processo de envelhecimento, pode-se desenvolver um perfil de idade compreensivo para qualquer indivíduo. Por exemplo, uma mulher de 70 anos pode ter uma boa saúde (idade biológica), mas ter problemas de atenção (idade psicológica). Essa mesma mulher pode se considerar uma excelente professora de línguas, mais do que uma avó. As medidas de idade cronológica, biológica, psicológica e social são relevantes e importantes para a compreensão do processo de envelhecimento, mas não para a sua determinação, pois a velhice é apenas uma fase da vida, como todas as outras, e não existem marcadores do seu começo e do seu fim.

Quando se leva em consideração somente a idade cronológica, está-se falando apenas da passagem do tempo sob o aspecto numérico, ao invés de consi- derar o envelhecimento como um fenômeno mais amplo no qual outros fatores participam e podem contribuir na variação das intempéries da passagem do tempo. Desta forma, biologicamente, os eventos ocorrem em um período de tempo, mas não por causa dele.

O envelhecimento é um processo complexo e multifatorial. A variabilidade de cada pessoa (genética e ambiental) acaba impedindo o estabelecimento de parâmetros. Por isso, o uso somente do tempo (idade cronológica) como medida esconde um amplo conjunto de variáveis. A idade em si não determina o envelhecimento, ela é apenas um dos elementos presentes no processo de desenvolvimento, servindo como uma referência da passagem do tempo.

Os termos criança, adolescente e adulto são usados na vida diária sem nenhum questionamento, no entanto, o termo velho suscita desagrados, e algumas pessoas até mesmo exigem que se deixe de usá-lo. Quando uma criança se torna adolescente, quando um adolescente se torna adulto e quando um adulto de torna idoso? Devido à falta de precisão entre o início e o fim de cada fase do desenvolvimento, estes são agrupamentos úteis, embora limitantes.

Na sociedade atual convive-se com diferentes tempos: o tempo do indivíduo e o tempo social. As regras sociais determinam o tempo para ir à escola, começar uma carreira, casar, ter filhos, ter netos e se aposentar. As pessoas procuram estar dentro do tempo social, sentindo-se mal quando estão atrasadas ou adiantadas. O tempo social é imposto às crianças, adolescentes, adultos e idosos e é um modelo linear de desenvolvimento do qual não se pode fugir. Ele define também em que momento as pessoas são consideradas velhas. Desta forma, a velhice é uma construção social e cultural, sustentada pelo preconceito de uma sociedade que quer viver muito, mas não quer envelhecer.

O uso de inúmeros termos e expressões para se referir às pessoas mais velhas e à velhice revela a existência de preconceitos sociais por parte da sociedade e do próprio indivíduo que envelhece. Ao longo das últimas décadas, cada vez mais os indivíduos envelhecem, mas não querem parecer velhos, pois na sociedade brasileira o idoso carece de maior valorização.

Como o Brasil não é mais um país de jovens, mas sim um país que está envelhecendo, com mais de 
15 milhões de pessoas com 60 anos ou mais, estima-se que a maior valorização do idoso possa se concretizar em um futuro próximo, no qual a tendência seria rever os estereótipos associados à velhice. A visão do envelhecimento como sinônimo de doença e perdas evoluiria para a concepção de que esta fase do ciclo vital é um momento propício para novas conquistas e para a continuidade do desenvolvimento e produção social, cognitiva e cultural. As experiências e os saberes acumulados ao longo da vida seriam vistos como ganhos que podem ser otimizados e utilizados em prol do próprio indivíduo e da sociedade. Dentro desta perspectiva, a velhice passaria a ser considerada uma fase boa da vida, não rotulada apenas pelas perdas, mas também reconhecida pelos ganhos e pela administração das transformações, cabendo ao idoso potencializar os próprios recursos e atuar na autoconstrução da subjetividade e da identidade.

Quais serão os efeitos culturais e sociais do número crescente de pessoas idosas na população? As pessoas idosas serão consideradas por suas famílias e comunidades como pessoas respeitáveis ou como pessoas não produtivas?

\section{Referências}

Andrews, M. (1999). The seductiveness of agelessness. Ageing and Society, 19 (3), 301-318.

Andrews, M. (2000). Ageful ans proud. Ageing and Society, $20(6), 791-795$

Araújo, L. F., \& Carvalho, V. A. M. L. (2005). Aspectos sócio-históricos e psicológicos da velhice. Revista de Humanidades, 6 (3), 1-9.

Argimon, I. L., \& Stein, L. M. (2005). Habilidades cognitivas em indivíduos muito idosos: um estudo longitudinal. Cadernos de Saúde Pública, 21 (1), 64-72.

Bee, H. (1997). O ciclo vital. Porto Alegre: Artes Médicas.

Berger, K. S. (1994). The developing person through the life span. New York: Worth Publishers.

Bytheway, B. (1995). Agism. Buckingham: Open University Press.

Bytheway, B. (2000). Youthfulness and agelessness: a comment. Ageing and Society, 20 (6), 781-789.

Costa, E. F. A., \& Pereira, S. R. M. (2005). Meu corpo está mudando o que fazer? In J. L. Pacheco, J. L. M. Sá, L. Py \& S. N. Goldman (Orgs.), Tempo rio que arrebata (pp.13-25). Holambra: Setembro.
Debert, G. G. (1999). A reinvenção da velhice: socialização e processos de reprivatização do envelhecimento. São Paulo: Universidade de São Paulo/Fapesp.

Estatuto do Idoso: (2003). Lei $n^{\circ} 10.741$, de 1 de outubro de 2003. Dispõe sobre o estatudo do idoso e das outras providências. Brasília: Senado Federal.

Ferreira, A. B. H. (2000). Miniaurélio século XXI escolar: o minidicionário da Língua portuguesa. Rio de Janeiro: Nova Fronteira.

Gibson, H. B. (2000). It keeps us young. Ageing and Society, 20 (6), 773-339.

Helman, C. G. (2005). Cultural aspects of time and ageing: time is not the same in every culture and every circumstance; our views of ageing also differ [Special Issue]. European Molecular Biology Organization, 6 (S1), S54-S58

Hoyer, W. J., \& Roodin, P. A. (2003). Adult development and aging. New York: The McGraw-Hill.

Jones, R. L. (2006). 'Older people' talking as if they are not older people: positioning theory as an explanation. Journal of Aging Studies, 20 (1), 79-91.

Neri, A. L. (2001a). O fruto dá sementes: processos de amadurecimento e envelhecimento. In A. L. Neri (Org.), Maturidade evelhice: trajetórias individuais e socioculturais (pp.11-52). Campinas: Papirus.

Neri, A. L. (2005). Palavras-chaveem gerontologia. Campinas: Alínea.

Neri, A. L., \& Freire, S. A. (Orgs.). (2000). E por falar em boa velhice. Campinas: Papirus.

Pacheco, J. L. (2005). Sobre a aposentadoria e envelhecimento. In J. L. Pacheco, J. L. M. Sá, L. Py \& S. N. Goldman (Orgs.), Tempo rio que arrebata (pp.59-73). Holambra: Setembro.

Papalia, D. E., Olds, S. W., \& Feldman, R. D. (2006). Desenvolvimento humano. Porto Alegre: Artmed.

Prado, S. D. (2002). O curso da vida, o envelhecimento humano e o futuro. Textos Envelhecimento, 4 (8), 1-12.

San Martín, H., \& Pastor, V. (1996). La epidemiologia de la vejez. Rio de Janeiro: Atheneu.

Schroots, J. J., \& Birren, J. E. (1990). Concepts of Time and Aging in Science. In I. Birren, J. E. II. Schaie \& K. Warner (Orgs.), Handbook of the Psychology of Aging (pp.45-64). London: Academic Press.

Uchôa, E. (2003). Contribuições da antropologia para uma abordagem das questões relativas à saúde do idoso. Cadernos de Saúde Pública, 19 (3), 849-853.

World Health Organization. (2005). Envelhecimento ativo: uma política de saúde. Brasília: Organização Pan-Americana da Saúde.

Recebido em: 12/9/2006

Aprovado em: 9/11/2006 